\title{
Design Process for Global Service Learning Project
}

\author{
Youngbong Seo1), O-Kaung Lim²), Jiin Eom³)
}

\begin{abstract}
Creativity Station is a global service learning project that enables students with various majors from three countries of Korea, Indonesia, and Malaysia to join an international convergence team and solve their local problems based on their majors since 2012. To ensure the success of global service learning projects, the participating students and professors follow a five-step design process: Band, Issue, Ideate, Realize, and Deliver. The participants automatically arrive at the final step of Deliver once they follow the specific and logical missions defined for each step. The design process of Creativity Station is rapidly emerging as a standard platform for community service in Indonesia and spreading as a representative model of service learning. In order to investigate the effectiveness of the design process of Creativity Station, students' reviews were investigated before and after the project based on a questionnaire survey. The results indicate that the students' practice capability, communication skills, and ability to utilize their majors were improved.
\end{abstract}

Keywords : global service learning, Creativity Station, design process, Band, Issue, Ideate, Realize, Deliver

\section{Introduction}

Global service learning project aims at bringing services to local population through technical supports provided by a group of students with different majors. By participating in the project, the students expand their experiences as well as helping the local residents. To take advantage of this, Pusan National University has developed a learning process in improving the creativity of the students and proposed a design process that can be used especially in service learning. Since 2012, students from Korea, Indonesia, and Malaysia, have been working on an international interdisciplinary team which operates a global service learning project to solve the problems in developing countries by utilizing their knowledge in various fields[1][2]. Creativity Station is an innovative design process with creative thinking, problem solving, and communication skills on multidisciplinary global environment[3].

Figure 1 shows the three key parts of the Creativity Station and the universities that participated in the

Received(September 29, 2017), Review Result(1st: October 20, 2017, 2nd: November 15, 2017), Accepted(December 10, 2017)

${ }^{1}$ Office for Education Accreditation, Pusan Nat'1 Univ., Jangjeon-dong, Geumjeong-gu, Busan, Korea email: ybseo@pusan.ac.kr

${ }^{2}$ Dept. Mechanical Engineering, Pusan Nat'1 Univ., Jangjeon-dong, Geumjeong-gu, Busan, Korea email: oklim@pusan.ac.kr

${ }_{3}^{3}$ (Corresponding Author)Office for Education Accreditation, Pusan Nat'1 Univ., Geumjeong-gu, Busan, Korea email: jiin.eom@gmail.com

* This work was supported by a 2-Year Research Grant of Pusan National University. 
project. Korean students from 13 universities of southeast Korea including Pusan National University, Indonesian students from 4 universities, and Malaysian students from a single university participated in this project. Charging NOW, Pre-education, consists of an appropriate technology, design mapping practice, equipment utilization training, and cultural education. Either two credits or hours of service were given after the completion of engineering service design project last August in Indonesia. After this project, the participants shared engineering service activities with faculties of the universities at the final reflection meeting.

Creativity is an indispensable attribute to the students, and it is becoming more important than before as the complexity and diversity of future technologies grows[4]. Generally, creativity is made up of six factors: the process, environments, and outputs are controllable factors, while personal characteristics, knowledge, and intelligence are uncontrollable factors. Creativity Station help students to elevate their creativity by teaching them to follow the proper design process based on the controllable factors of creativity. The participants follow the process and perform their assigned missions, and thus, they improve their thinking ways by shifting from the normal thinking to process thinking and up to creative thinking. There are already several educational programs in Indonesia based on Creativity Station and they have followed the standard design process which was developed by Pusan National University. Therefore, it could be predicted that the further development and applications of the design process will contribute to settle a standard platform for community service and spread a representative education model of service learning. In this paper, the design process of Creativity Station and the possibility for standard platform of community service in Indonesia is proposed.

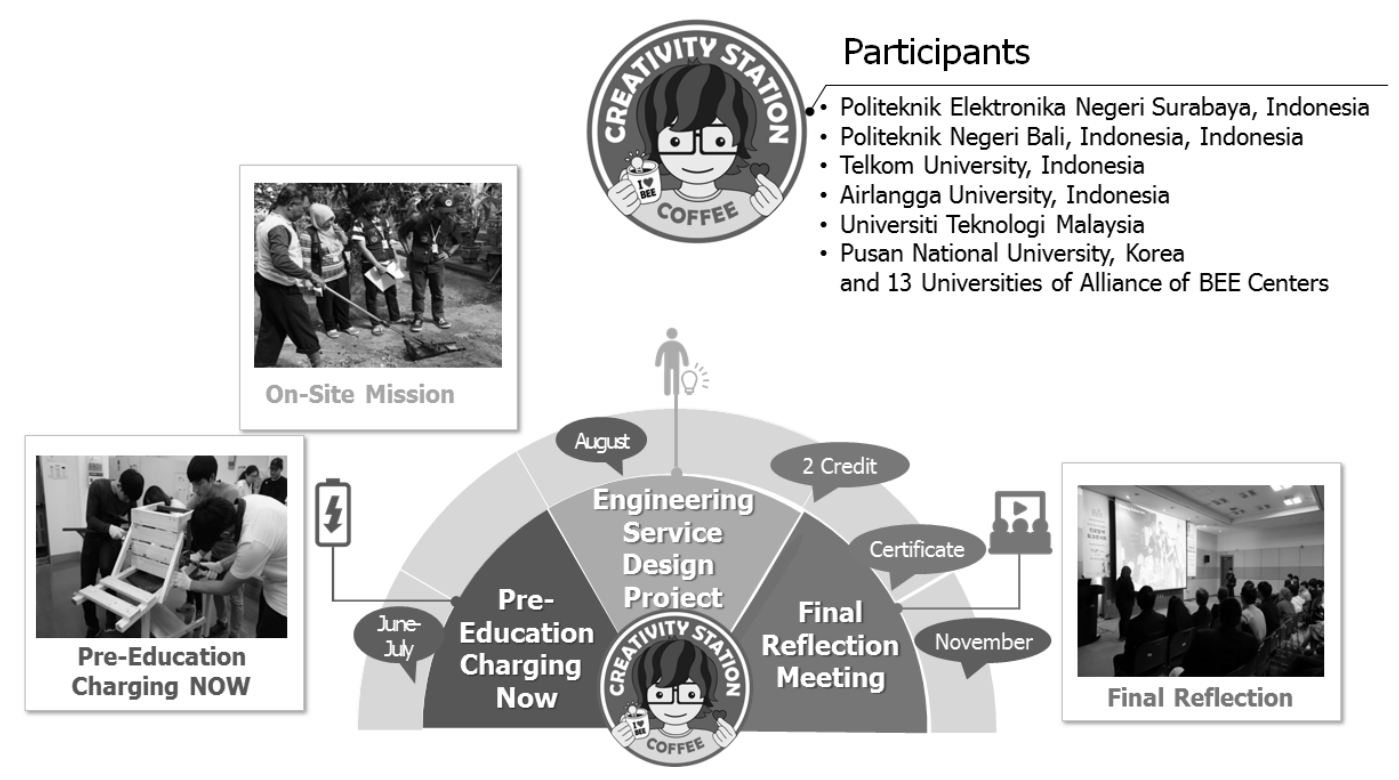

[Fig. 1] Three Key Parts of Creativity Station

\section{Design Process of Creativity Station}


The overall flow of design process missions in Creativity Station is shown in Figure 2. The design process of Creativity Station consists of five steps: Band, Issue, Ideate, Realize, and Deliver. Each step presents simple missions to perform the design process as depicted in Table 1. Most of the issues can be solved by this process, and the best results will be realized by the given design process.

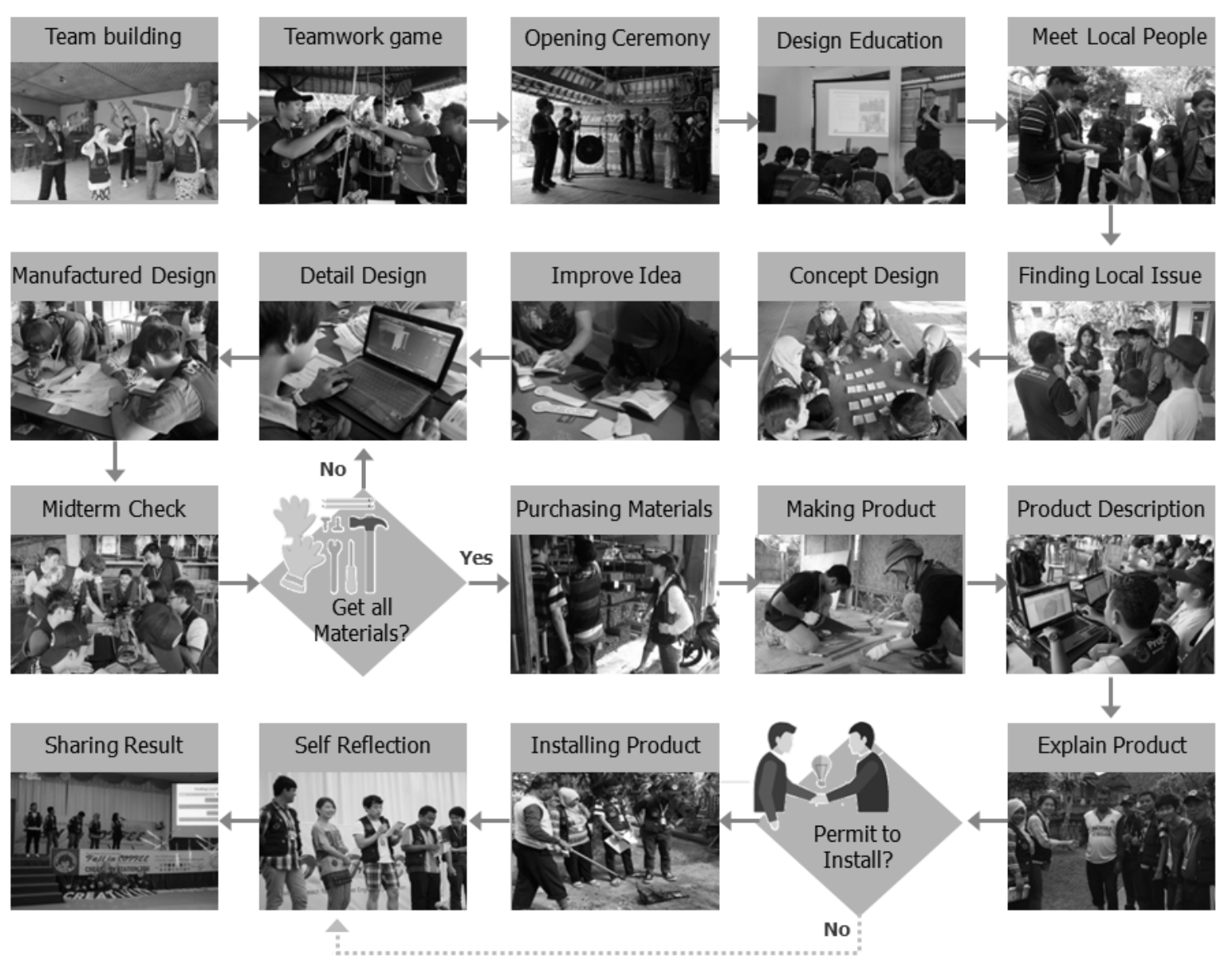

[Fig. 2] Overall Flow of the Design Process Missions

[Table 1] Missions of Design Process

\begin{tabular}{|c|c|c|c|c|c|}
\hline $\begin{array}{c}\text { Step } \\
\text { (Symbol) }\end{array}$ & 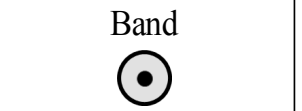 & $\begin{array}{l}\text { Issue } \\
\bullet\end{array}$ & $\diamond$ & $\begin{array}{c}\text { Realize } \\
\bullet\end{array}$ & Deliver \\
\hline $\begin{array}{c}\text { Missions } \\
\text { of Design } \\
\text { Process }\end{array}$ & $\begin{array}{l}\text { Break Ice } \\
\cdot \text { Build Teams } \\
\text { - Play Teamwork Games } \\
\cdot \text { Take a Mbrning Walk }\end{array}$ & \begin{tabular}{|l} 
- Observe Sites \\
- Make Questions \\
- Interview People \\
- Summarize Situations \\
- Define Problems \\
- Choose Problems
\end{tabular} & $\begin{array}{l}\text { - Design Concepts } \\
\text { - Improve Ideas } \\
\text { - Design Details } \\
\text { - Assembly Order }\end{array}$ & $\begin{array}{l}\text { - Purchase Materials } \\
\text { - Plan Work } \\
\text { - Make Products } \\
\text { - Describe Products }\end{array}$ & $\begin{array}{l}\text { - Install Products } \\
\text { - Evaluate Results } \\
\text { - Do Self Reflection }\end{array}$ \\
\hline
\end{tabular}

Band presents the missions to improve teamwork for the successful project. Students should determine the job in the team considering the personality types and specialties. Students are divided into teams, and each team should determine its job, considering the personality types and specialties of its members. There are six 
jobs, consisting of designer, communicator, journalist, accountant, scheduler, and mapper. Each team defines a team name, a slogan, and five team rules that can represent the team well.

Issue defines the problems through direct visitation of the site, interviews with residents and observation of the local site. Students analyze the problem factors causing the issues in each problem situation so that the problems can be analyzed accurately and concretely. The process of Issue is shown in Figure 3. Students observe the site and write the questionnaires for interviewees with the empathy of local people. Students find each problem factor from the problem situation and then define the problems. Finally, one problem is selected as the main one to be solved based on the problem evaluation criteria, such as urgency, repeatability, and simplicity.

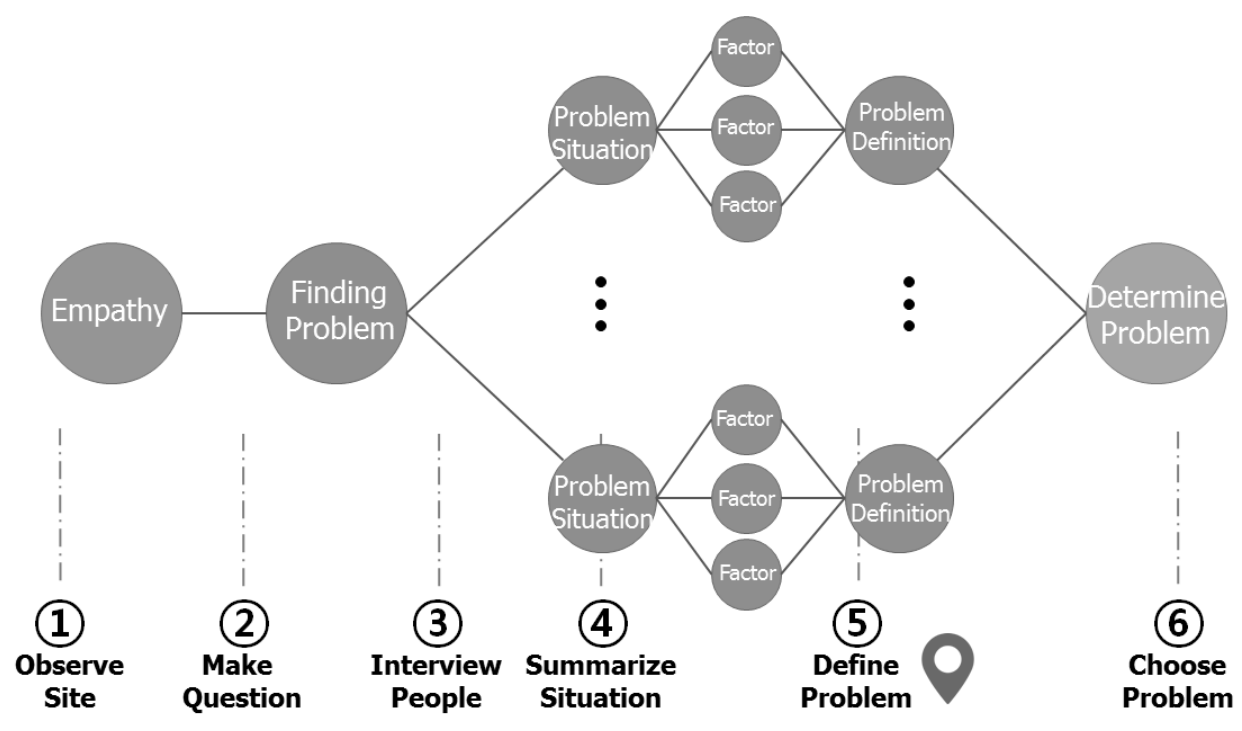

[Fig. 3] The Process of Issue

Besides these two, there are three other steps as mentioned before. Ideate leads to deriving and improving ideas, concept design and assembly order for problem solving. Ideas are derived through brainstorming, selected based on evaluation criteria, and improved using PMI (Plus, Minus and Interesting) method. The idea-based products are designed in detail based on these processes. Realize includes purchasing of materials, planning, making and describing the products. The products are manufactured in consideration of the limited material cost, local availability of materials, and the entire production period. Deliver includes product installation after the approval of local residents, self-assessment and self-reflection. The product will be installed, and the local user will be provided with instructions on its usage and maintenance.

To make the results from the five-step design process concrete, the team managers are assigned to the professors from three countries with various majors. The manager acts as an observer and consultant during the steps of Band and Issue and is not assigned to a specific team. After the issues are decided by each team, the 
manager is matched in consideration of his own specialty, suitability and team personality. From the Ideate step to Deliver, the manager supervises the students as a mentor and guides them to achieve their final goals. Figure 4 shows the manager roles in each step.

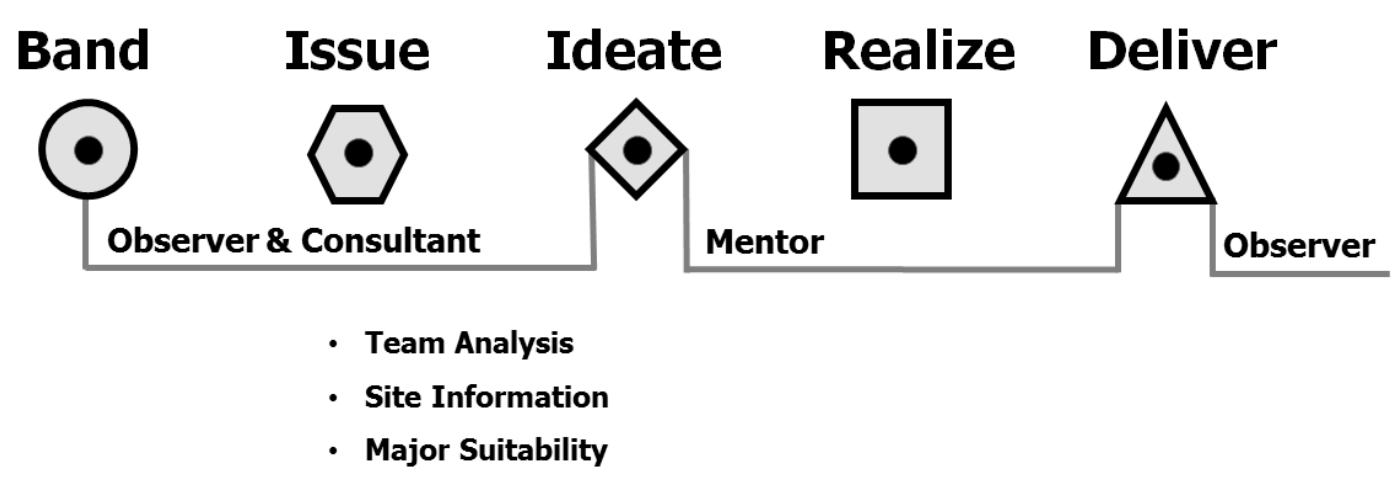

[Fig. 4] Manager Matching in Creativity Station

As shown in Figure 5, Creativity Station extends the concept of design thinking[5] from a class of campus to a site of local area and from the prototype to a real product. Before identifying the issues, the Band step is setup to form the optimal team in solving the problem. In the Deliver step, an actual product can be produced and delivered to the local residents.

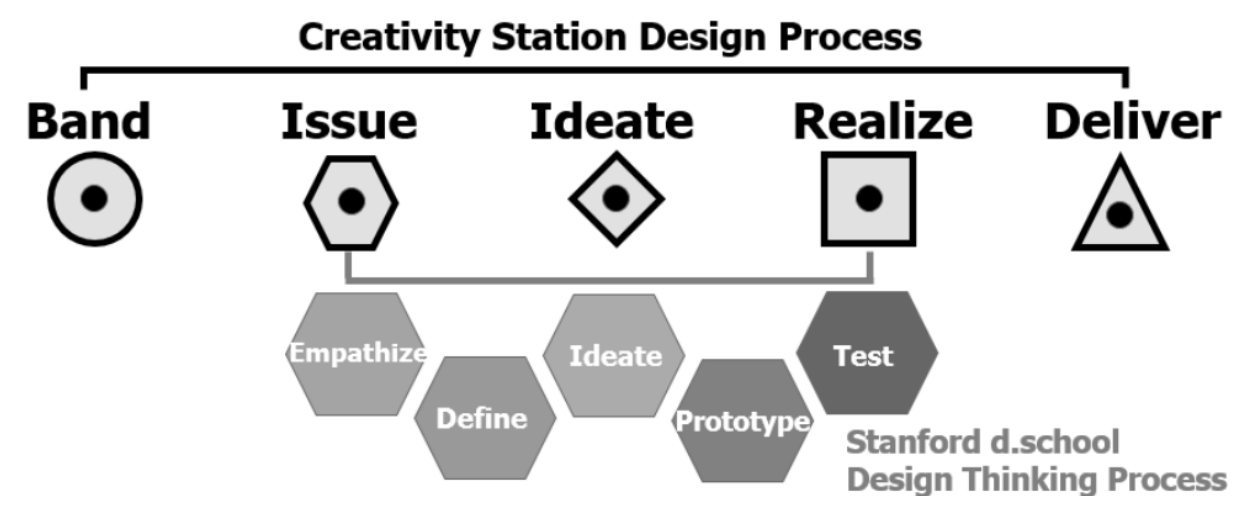

[Fig. 5] Design Process vs. Design Thinking

All activities of Creativity Station can be shared using the web-site WINDboy.org. WIND stands for World Issue And Design, and this site makes it possible to map the local issues, the design process, and the solutions at the certain location. The updated information for service learning can be listed and utilized by the students, universities, companies, NGOs, and governments. The participants should upload at least one photo with the issue description of the places where they have worked. The uploaded information of WINDboy is classified into three colors to display the current states. In figure 6, the red icon indicates a problem that has not been solved yet, the yellow icon indicates a problem that is currently in progress, and the blue icon indicates that 
the project has been completed with solutions.

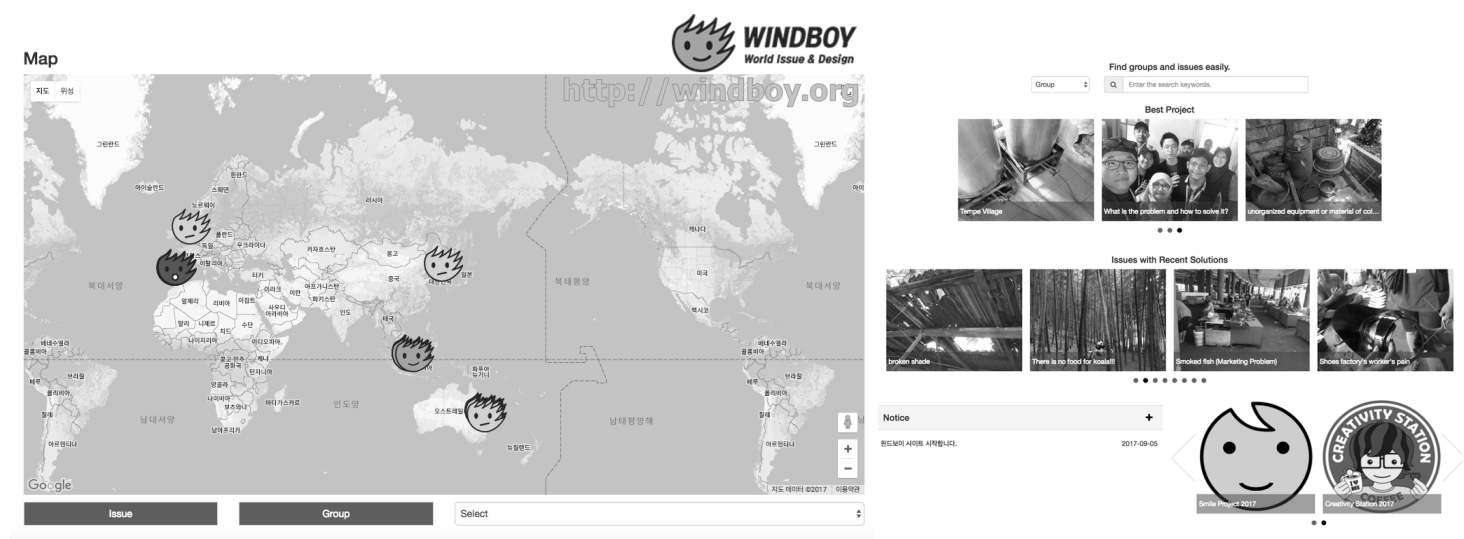

[Fig. 6] Sharing of Service Learning Project in WINDBoy.org

\section{Survey on the Program Outcomes}

There are five groups of a standard platform of community services to utilize BIIRD ESL (Engineering Service Learning) model as shown in Figure 7. Universities use this model for education and research, while the students use it for learning. The government invests its budget in the right place to see the performance of the model, the community seeks help, and the industry uses it to secure potential customers. The current government of Indonesia places a great importance on the community service activities of universities. The design process of Creativity Station is rapidly emerging as a standard platform for community services in Indonesia and spreading as a representative model of service learning. In this regard, the EEPIS (Electronic Engineering Polytechnic Institute of Surabaya) and Telkom University in Indonesia have led the spread of standard platforms of community services across Indonesia. The EEPIS and Telkom University already have developed their own service learning models and operated the whole process based on Creativity Station. EEPIS has "Dynamic Island", a multimedia service learning program and "Slice Project", a computer science service learning program. Telkom University has the ESC (Engineering Service Community), which is carrying out engineering service projects in November every year.

The program outcomes were evaluated by the questionnaire survey conducted to the participants in Creativity Station 2017. The survey was carried out on 63 participants before they get involved and after they finished the whole project. Through the surveys done before and after the project, the same questions per program outcomes were used to analyze the achievements of several missions that the students have performed. There are 48 questions asked and each question is related with the program outcomes. Inquiries were made about grade, gender, duty, and major in order to standardize a sample group. All achievement degrees were increased 
especially the practice capability, communication skills, and the ability to utilize their majors as shown in Figure 8.

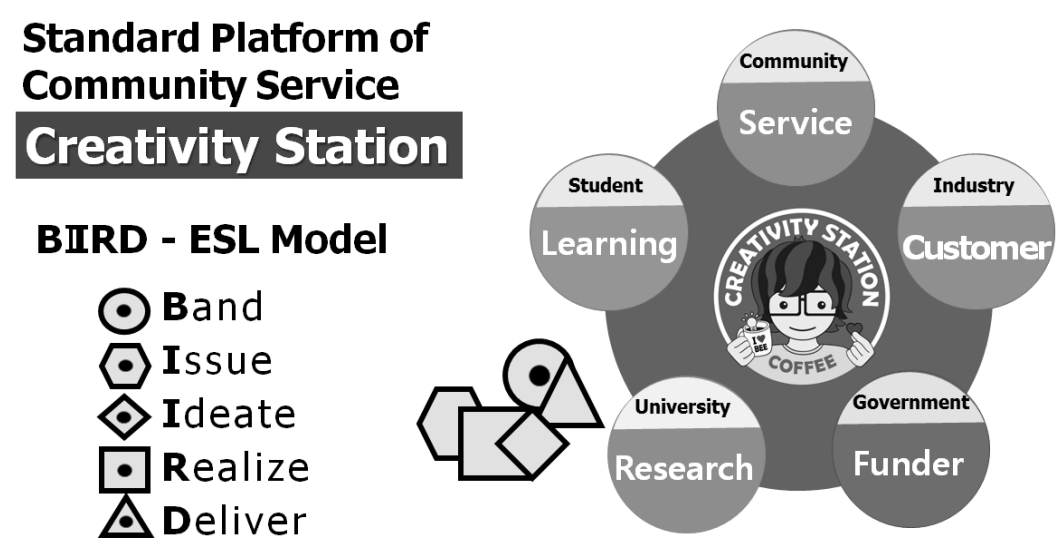

[Fig. 7] BIRD (ESL Model), Standard Platform of Community Service

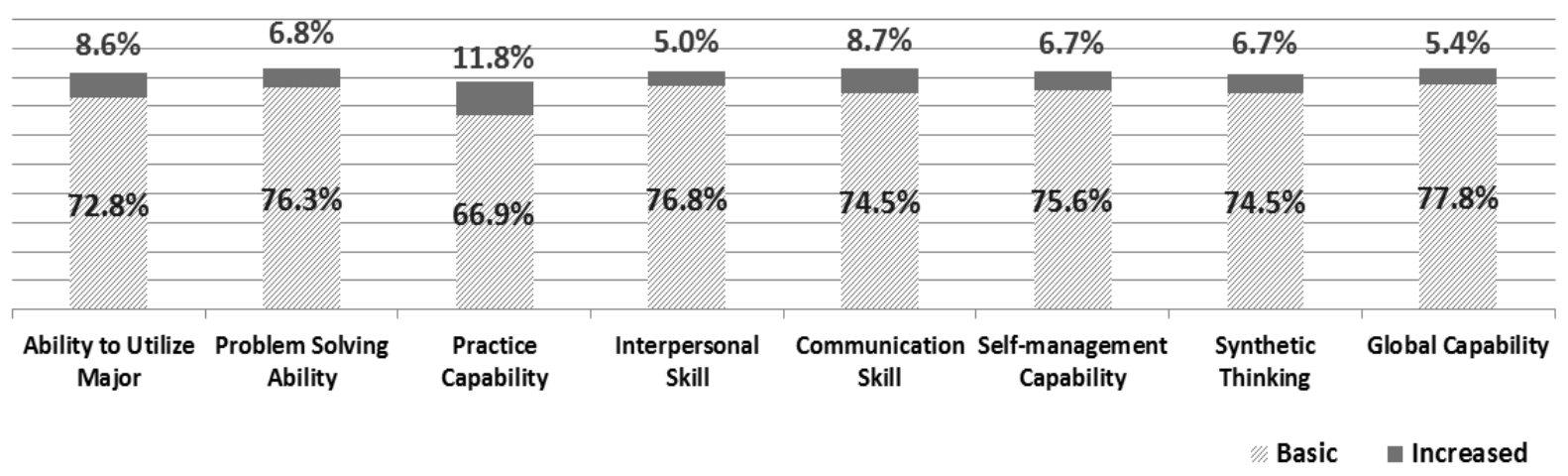

[Fig. 8] Improvement of Program Outcomes in Creativity Station 2017

According to the reflections of the participants, the students were generally satisfied with this program and increased the problem solving ability, communication skills, team collaboration ability, and global capability. The following are some of the reflections of the participating students.

- The activities of Creativity Station provided an experience in how to increase teamwork and I could solve the problems by the design process. I feel very fortunate to have an opportunity to participate in these activities.

- I have learned so many valuable lessons and also got a lot of experience throughout this program.

- I have now realized the importance of having confidence when giving out my personal opinions. I have trained myself to be more disciplined and to maintain my cool when conducting group discussions.

- I learned how to behave and communicate well so that people around us feel comfortable.

- I could learn to work with my team and manage time. I got lots of new friends, new experiences, and new engineering knowledge. 
- In this program, I understood how to unite thoughts from different backgrounds and knew how to respect each other.

\section{Conclusion}

The design process of Creativity Station was proposed to ensure the success of a global service learning project by Pusan National University. The design process has five steps, namely, Band, Issue, Ideate, Realize, and Deliver, and each step presents simple missions for the participating students to perform. As a method to investigate the students' responses toward the design process of Creativity Station, questionnaire survey was conducted before and after the project. The results have shown that the students' practice capability, communication skills, and the ability to utilize their majors were improved significantly. In fact, the design process was widely adopted in Indonesia and would be a representative model of service learning in the future. In addition, in order for the design process to be a standard platform of community services for not only the participating students but also for universities, governments, communities, and industries, it needs to be further developed and should be applied to much more areas than at present.

\section{References}

[1] Young Bong Seo, Jiin Eom and O-Kaung Lim, Global Engineering Service Design Project - Creativity Station (Korean Edition), Bookshill (2014)

[2] Y. Seo, J. Eom, M. Jeong, Y. Kim, and O. Lim. Analysis of Program Outcomes in Project BEE Outreach Together 2012. Proceedings of the 4th IEEE Global Engineering Education Conference, (2013) March 13-15; Berlin, Germany.

[3] Y. Seo, J. Eom, M. Jeong, M. Kim, J. Kim and O. Lim. Design Thinking of Creativity Station Based on Engineering Service Learning. Proceedings of the 4th Asian Conference on Engineering Education, (2014) October 10-12; Kumamoto, Japan

[4] National Academy of Engineering, The Engineer of 2020: Visions of Engineering in the New Century, Washington DC (2004)

[5] Riverdale, IDEO, Design Thinking for Educators Toolkit, https://designthinkingforeducators.com/toolkit/, (2013) 